\title{
Trend Analysis of the Research on Construction Grammar in CSSCI Journals from 2010 to 2020
}

\author{
Xinyu Lun* \\ International College, Macau University of Science and Technology, Macau 999078, China \\ *Corresponding author: Xinyu Lun, 2009853put30001@ student.must.edu.mo
}

\begin{abstract}
This study aims at analyzing the tendency and change in the research on construction grammar from 2010 to 2020 . Descriptively, this study includes the publication year, research topic, research direction, research content, and the research methods. Twenty-four CSSCI journals were selected as the research samples using the keyword - "Construction Grammar." The research topics mainly include Chinese construction research, foreign language construction research, and comparative studies on Chinese and other language constructions. The results showed that there are many Chinese construction research, but the other two research topics still require improvement. Ontology research was the main focus; acquisition research and teaching research are worthy for further exploration. Case studies and theoretical studies were the most concerned contents, whereas studies on language acquisition, pedagogy, and corpus construction were feeble. Qualitative description and theoretical review were the most popular methods, while empirical, quantitative, and diachronic analyses were less frequently used. After analyzing the trends, it has been predicted that the research on construction grammar would continue to heat up in the future, and there would be more research directions and contents along with diversified research methods.
\end{abstract}

Keywords: Construction grammar; Trend analysis; CSSCI journals

Publication date: November 2021; Online publication: November 30, 2021

\section{Introduction}

Construction grammar $(\mathrm{CxG})$ is a new grammar research concept that emerged in the United States in the 1980 s $^{[1]}$. Up to now, while many different types of competing variants of $\mathrm{CxG}$ could be found in literatures (Fillmore et al. 1988; Fillmore and Kay 1999; Goldberg 1995, 2003, 2006; Langacker 1987; Taylor 2002, Croft 2001), the most representative and influential one is the research represented by Goldberg [2], which takes case grammar, frame semantics, and gestalt grammar as the theoretical basis, guiding the readers to view languages from the perspective of function and gestalt cognition.

After more than 30 years of development, it has presented an ascendant trend. Tens of thousands of articles, books, and academic conferences have focused on construction grammar until 2020. In the last decade, the International Conference on Construction Grammar (ICCG) has demonstrated a strong momentum of the research on construction grammar, with interdisciplinary integration and multiperspective application. In 2018, the Language Teaching and Linguistic Studies, a core linguistics journal in China, launched a special issue on the "Theory and Applied Research of Construction Grammar," discussing theories based on construction grammar, ontology, second language teaching, and acquisition. It can be confirmed that construction grammar attracts many language researchers with its strong theoretical tension, description, and explanatory power.

In the past ten years, the research on construction grammar has been characterized by the extension of the research scope, diversified research methods, and increasing crossover with other fields. To study construction grammar in detail, discussing the core problems, research hot spots, research blind spots, 
research methods, theoretical construction, and future development of the research achievements in the past ten years, as well as clearly presenting the opportunities and challenges faced by construction grammar, is of profound practical significance.

\section{Literature review}

In previous studies, many scholars have described the development of construction grammar from theoretical review. Descriptively, Jin Shengxi ${ }^{[3]}$ and Fan Zhenqiang ${ }^{[4]}$ found that international research focused on construction and grammar, English and language, usage and acquisition, etc., making more significant breakthroughs in foreign language acquisition research and argumentation structure research. Based on Citespace, $\mathrm{Wu}$ Xia showed that Chinese $\mathrm{CxG}$ needs to be improved in terms of theory construction, discipline cooperation, and research methodology construction ${ }^{[5]}$. In terms of qualitative research, Mao Jiguang claimed that there are many branches of $\mathrm{CxG}$ by summarizing the theoretical basis and five theoretical models of $\mathrm{CxG}$, which are interwoven ${ }^{[6]}$. Zhang Juan sorted out the theoretical connotation and application research of the development of Chinese $\mathrm{CxG}$ and suggested that the prominent features of Chinese $\mathrm{CxG}$ research is that theoretical discussion has been carried out, while application research is groping and has just started ${ }^{[7]}$. To sum up, scholars have paid much attention to the development direction of CxG. However, only a few articles have analyzed the characteristics, changes, and differences of existing $\mathrm{CxG}$ research in terms of the research topic, publication year, research content, research direction, and research method.

\section{Methodology}

As a type of quantitative research, research trend analysis can be used to summarize previous study and provide direction for researchers to deal with the possible difficulties in the future. This paper has adopted this method to analyze the tendency and change of $\mathrm{CxG}$ research from 2010 to 2020 in terms of publication year, research topic, direction, content, and methods, by statistical calculation and coding.

CSSCI, known as Chinese Social Sciences Citation Index, is a database developed by the Chinese Social Sciences Research and Evaluation Center of Nanjing University. It is used to retrieve the collection and citation of papers in the field of Chinese social sciences. The selected journals are academic ones with high educational value, significant influence, and relatively representative. The literatures retrieved from 24 CSSCI journals (Contemporary Rhetoric, Contemporary Linguistics, Dialect, Research in Ancient Chinese Language, Chinese Linguistics, Chinese Language Learning, Minority Languages of China, Shanghai Journal of Translators, Chinese Teaching in the World, Journal of Foreign Languages, Technology Enhanced Foreign Languages, Foreign Language Education, Foreign Language Teaching, Foreign Language Teaching and Research, Foreign Language World, Foreign Language and Foreign Language Teaching, Modern Foreign Languages, Linguistic Researches, Language Teaching and Linguistic Studies, Linguistic Sciences, Applied Linguistics, Chinese Translators Journal, Foreign Languages in China, and Studies of the Chinese Language) with the theme of "Construction Grammar" should be adequate and representative. Besides bibliographic conference introduction, essay solicitation, review articles, new publication information, and other contents, 689 pieces of literature were selected as research samples.

\section{Data analysis}

A total of 689 pieces of literature have been analyzed with statistical methods. They were classified into three types: Chinese construction research, foreign language construction research, and comparative study 
of Chinese and other language constructions, with 567, 84, and 38, respectively.

\subsection{Publication year}

It can be seen from Figure 1 that the year with the highest number of publications was 2015, while the lowest number was in 2020 .

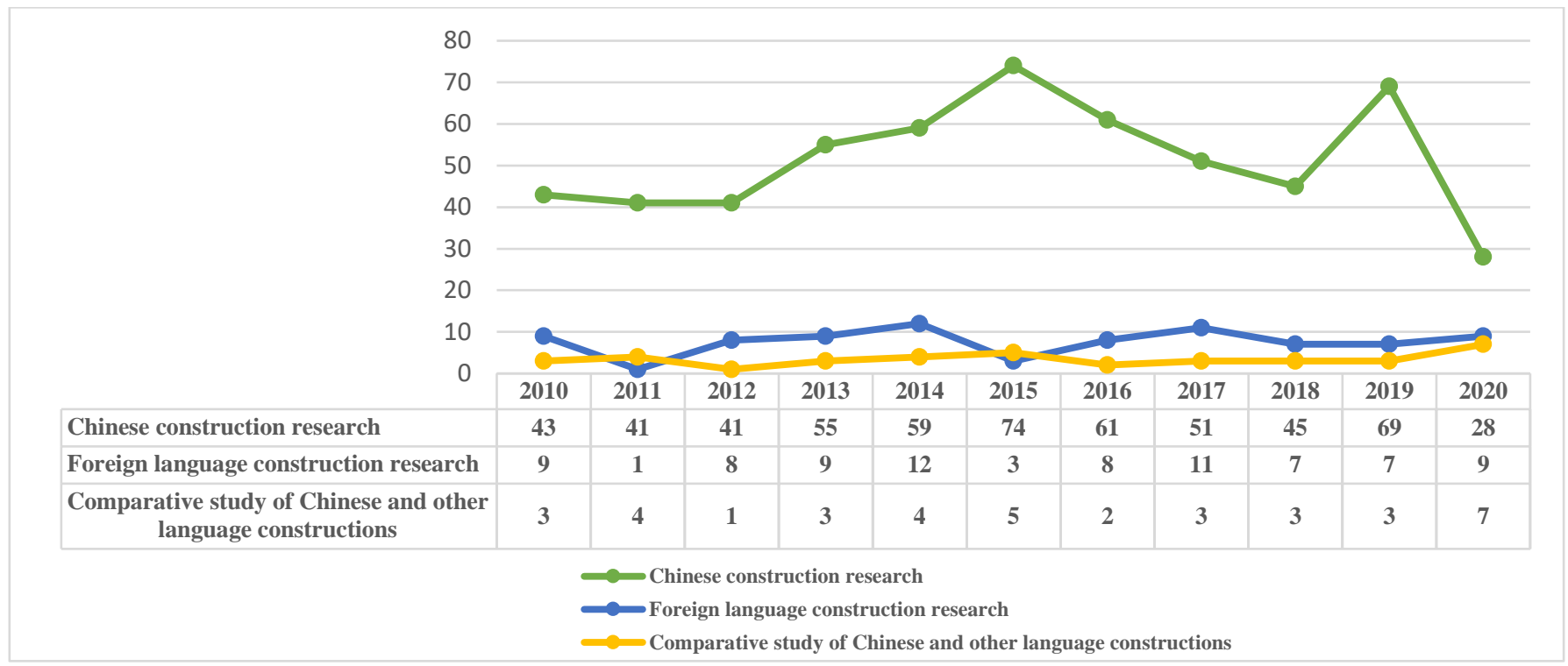

Figure 1. Publication year

In the past decade, the average number of research papers on Chinese $\mathrm{CxG}$ published in CSSCI journals was 51.5 per year. From 2011 to 2014, the number of papers increased gradually, from 41 to a peak of 74 . However, from 2015 to 2018, the number slowly declined, and then rose sharply in 2019, reaching a second peak with 69 papers. After that, the number showed a dramatic decline, with only 28 papers in 2020, the lowest number in the recent ten years. The trend indicates that before 2015, the enthusiasm for studying Chinese CxG among the academic community was heated. After 2015, the research reached a cooling-off period, which lasted for about three years. It broke-off in 2019 but resumed in 2020.

The number of papers on foreign language construction research was 7.6 per year on average in the past decade. After reaching the lowest value of 1 in 2011, it steadily increased and reached a peak of 12 in 2014. After dropping to 3 , the second lowest value, in 2015 , the number increased for two consecutive years and reached the second-highest value of 11 in 2017. The number of publications from 2017 to 2020 was relatively stable, with a consensus around 8.

The number of papers on the comparative study of Chinese and other language constructions was 3.5 on average per year in the past decade. It reached the lowest value of 1 in 2012, fluctuated from 2013 to 2019, and reached the highest value of 7 in 2020.

\subsection{Research direction}

The research direction of construction grammar can be generally divided into ontology research, acquisition research, and teaching research. According to the content of the studies, all the samples have been arranged and coded in an ascending or descending chronological order. The code of a single research direction is 1 ; if two research directions exist simultaneously, the code is 0.5 ; if three exist simultaneously, the code is 0.33 . Table 1 shows the coding. 
Table 1. Research direction

\begin{tabular}{|c|c|c|c|c|}
\hline & $\begin{array}{l}\text { Ontology } \\
\text { research }\end{array}$ & $\begin{array}{c}\text { Acquisition } \\
\text { research }\end{array}$ & $\begin{array}{l}\text { Teaching } \\
\text { research }\end{array}$ & Total \\
\hline Chinese construction research & 527.49 & 9.99 & 29.49 & 566.97 \\
\hline Foreign language construction research & 56.33 & 8.33 & 19.33 & 83.99 \\
\hline Comparative study of Chinese and other language constructions & 34.5 & 0 & 3.5 & 38 \\
\hline Total & 618.32 & 18.32 & 52.32 & 688.96 \\
\hline
\end{tabular}

On the whole, the highest proportion among the three topics was ontology research, while acquisition research had the least. Descriptively, in Chinese $\mathrm{CxG}$ studies and comparative studies, ontology research accounted for over $90 \%$, while neither acquisition nor teaching research accounted for more than $10 \%$. In contrast, acquisition research and teaching research in foreign $\mathrm{CxG}$ research were more significant.

The trend of ontology research in Chinese $\mathrm{CxG}$ research was relatively the same as the trend of papers published. There were small fluctuations in acquisition research and teaching research, but their trends remained sluggish. This shows that ontology research was the mainstream direction of Chinese $\mathrm{CxG}$ research. Acquisition research and teaching research in Chinese $\mathrm{CxG}$ research were relatively weak and have an extensive research space. Ontology research in foreign $\mathrm{CxG}$ research dropped to its lowest value in 2011 and 2015 but reached 9.5 in 2014. The fluctuations in teaching and research have been on the rise, and the rising momentum was quite significant in the recent three years. Ontology research in comparative studies peaked in 2020, while teaching research were only a few. No papers were found in the field of acquisition research from construction comparison in CSSCI journals (Table 2).

Table 2. Research direction

\begin{tabular}{cccccccccc}
\hline \multirow{2}{*}{ Year } & \multicolumn{2}{c}{ Chinese construction research } & \multicolumn{3}{c}{ Foreign language construction research } & \multicolumn{3}{c}{$\begin{array}{c}\text { Comparative study of Chinese and } \\
\text { other language constructions }\end{array}$} \\
\cline { 2 - 9 } & Ontology & Acquisition & Teaching & Ontology & Acquisition & Teaching & Ontology & Acquisition & Teaching \\
\hline 2010 & 39.5 & 2 & 1.5 & 8.33 & 0.33 & 0.33 & 3 & 0 & 0 \\
2011 & 39 & 0 & 2 & 1 & 0 & 0 & 4 & 0 & 0 \\
2012 & 37.33 & 1.33 & 2.33 & 4 & 2 & 2 & 1 & 0 & 0 \\
2013 & 49.83 & 0.83 & 3.33 & 6.5 & 1.5 & 1 & 3 & 0 & 0 \\
2014 & 58 & 0 & 1 & 9.5 & 0 & 2.5 & 3.5 & 0 & 0.5 \\
2015 & 69 & 1.5 & 4.5 & 1 & 1 & 1 & 5 & 0 & 0 \\
2016 & 56 & 2 & 3 & 6 & 0 & 2 & 2 & 0 & 0 \\
2017 & 46.5 & 0.5 & 4 & 5 & 0.5 & 5.5 & 1 & 0 & 2 \\
2018 & 41.5 & 0 & 3.5 & 4 & 1 & 2 & 3 & 0 & 0 \\
2019 & 65.5 & 1.5 & 2 & 5 & 1 & 1 & 2 & 0 & 1 \\
2020 & 25.33 & 0.33 & 2.33 & 5 & 1 & 2 & 7 & 0 & 0 \\
\hline
\end{tabular}

\subsection{Research content}

Under the three research directions, there are five main research contents:

(1) theoretical study on $\mathrm{CxG}$; 
(2) case study on $\mathrm{CxG}$;

(3) study on CxG second language acquisition (SLA);

(4) study on CxG pedagogy;

(5) study on $\mathrm{CxG}$ corpus.

Table 3 shows the coding of the research content of each article.

Table 3. Research content

\begin{tabular}{lcccccc}
\hline & $\begin{array}{c}\text { Theoretical } \\
\text { study on CxG }\end{array}$ & $\begin{array}{c}\text { Case study } \\
\text { on CxG }\end{array}$ & $\begin{array}{c}\text { CxG } \\
\text { SLA }\end{array}$ & $\begin{array}{c}\text { CxG } \\
\text { pedagogy }\end{array}$ & $\begin{array}{c}\text { CxG } \\
\text { corpus }\end{array}$ & Total \\
\hline Chinese construction research & 100.5 & 430 & 25.5 & 11 & 0 & 567 \\
Foreign language construction research & 8.5 & 50 & 16.5 & 9 & 0 & 84 \\
Comparative study of Chinese and other language constructions & 8.5 & 27 & 0 & 1.5 & 1 & 38 \\
Total & 117.5 & 507 & 43.5 & 20 & 1 & 689 \\
\hline
\end{tabular}

Case study was the main content among the three research topics. Theoretical studies were also common in Chinese CxG studies, while studies on CxG SLA, pedagogy, and corpus were relatively few. There were many studies on CxG SLA and some references on pedagogy and theoretical analysis in foreign language $\mathrm{CxG}$ research. In regard to comparative studies, the main contents were theoretical research and case studies.

Based on Figure 2, it can be seen that in Chinese $\mathrm{CxG}$ research, the range of case study was the largest, showing a gradual upward trend from 2011 to 2015, reaching a peak in 2015, and then dropping to its lowest value in 2020. Theoretical research was also a hot topic among the research topics; from 2010 to 2012, it showed a downward trend and then a sudden increase. From 2013 to 2018, it was more than 10, but thereafter, it gradually decreased. The total number of acquisition research and pedagogy research were few and fluctuated gently, reaching their peak in 2016 and 2019, respectively.

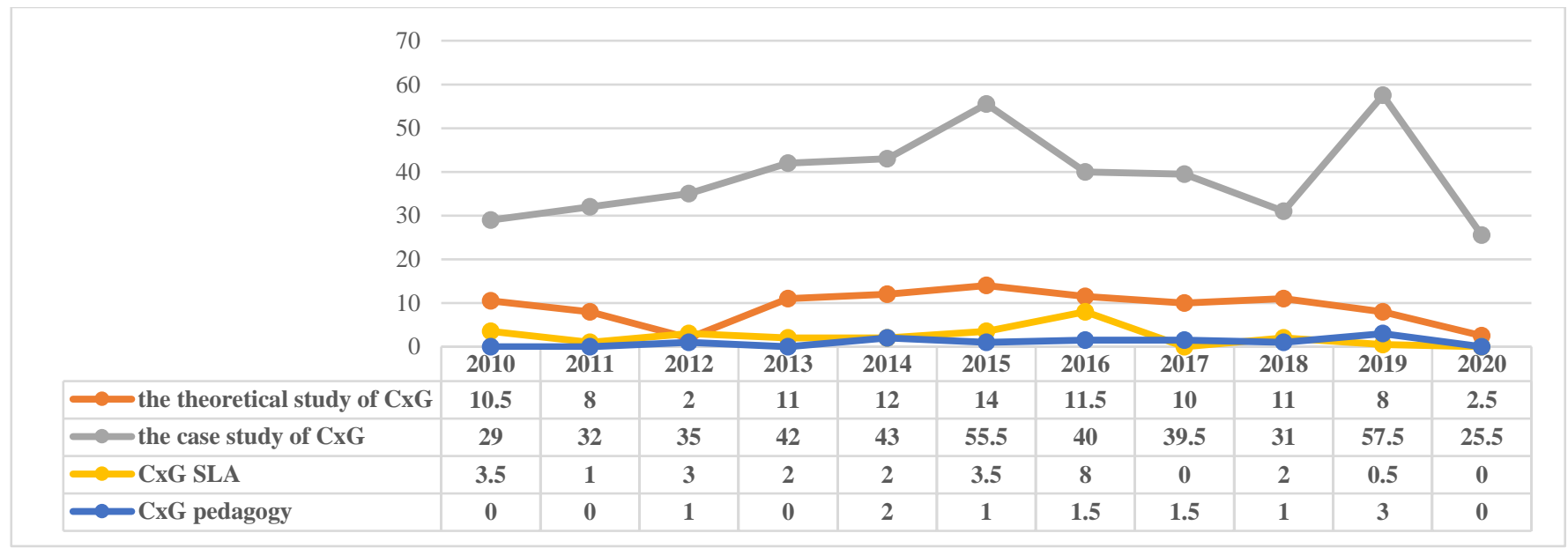

Figure 2. Research content in Chinese construction grammar research

As shown in Figure 3, foreign language $\mathrm{CxG}$ research had different focus every year, resulting in large fluctuations. Descriptively, case studies had three peaks, in 2010, 2013, and 2017, with two valleys, appearing in 2011 and 2015. Theoretical research reached its peak in 2014 to 2015; however, there were 
relatively few theoretical research in other years. SLA research reached its peak in 2012 and 2014; ever since then, it fluctuated. Pedagogy reached its peak in 2017 and fluctuated around two at different times.

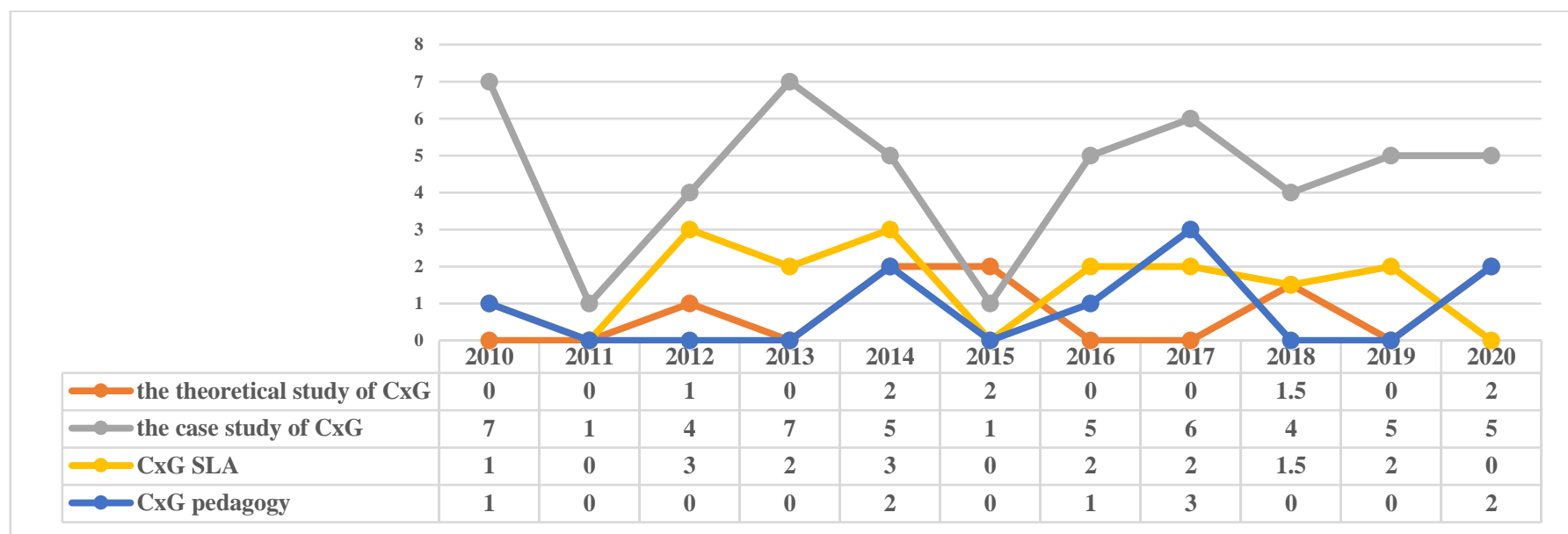

Figure 3. Research content in foreign language construction research

Figure 4 clearly shows that in comparative studies, the proportion of case studies fluctuated and reached its maximum value in 2020. Theoretical research reached its peak in 2011 but fell sharply and remained at low levels ever since then. Pedagogy and second language acquisition research appeared briefly in 2015 and 2012, respectively, but barely in other years. SLA research had been absent for nearly a decade.

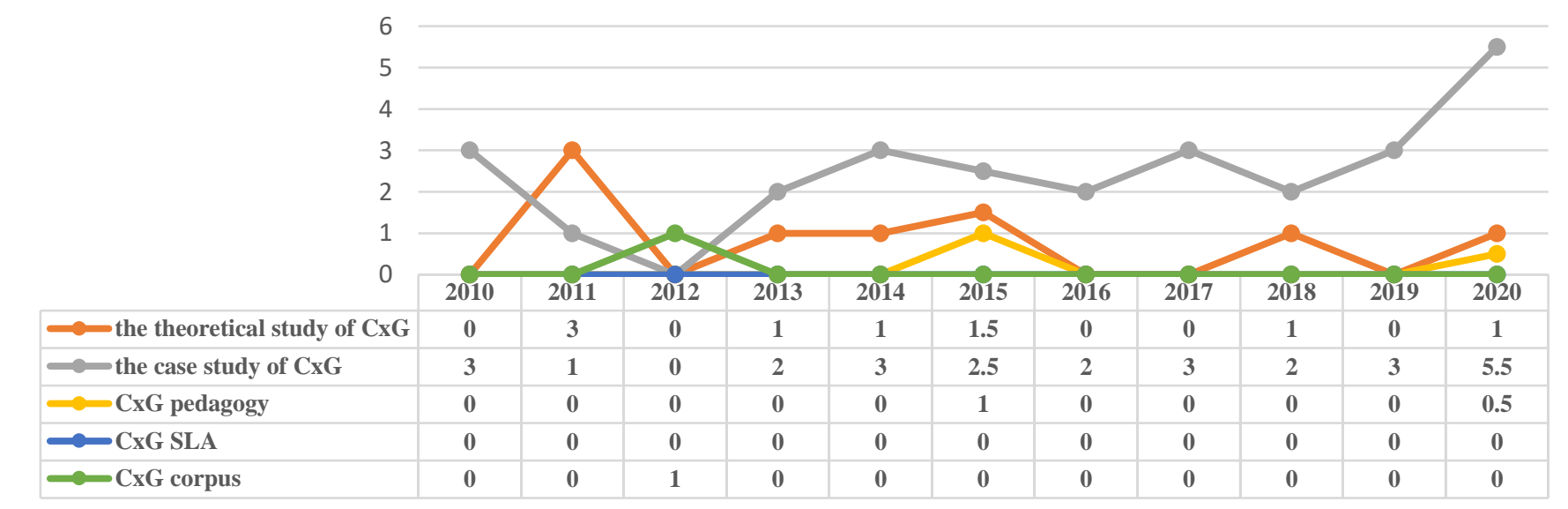

Figure 4. Research content in comparative studies of Chinese and other language constructions

\subsection{Research method}

Standard linguistic research methods include qualitative description, comparative analysis, empirical analysis, theoretical review and discussion, quantitative description, as well as diachronic analysis, which are also involved in $\mathrm{CxG}$ research. Descriptively, qualitative description is a case-based analysis of the construction. Comparative analysis includes comparing different constructions in Chinese or comparing similar constructions in other languages. Empirical analysis is an ontological method; it is an acquired or instructional analysis of constructs based on observation and experiment. Theoretical review and discussion usually review the existing $\mathrm{CxG}$ theory. Quantitative description is a synchronic method to analyze constructions based on language aggregation systems, such as corpus and database. Diachronic analysis explores constructs from the perspective of diachronic linguistics. 
Table 4 shows the results obtained by encoding the research methods of each article. Overall, qualitative description as well as theoretical review and discussion were the two most commonly used research methods. Compared with the other two research topics, comparative analysis was undoubtedly the primary method in comparison studies. Empirical research and quantitative research methods were frequently used in foreign language $\mathrm{CxG}$ research.

Table 4. Research methods

\begin{tabular}{|c|c|c|c|c|c|c|c|}
\hline & $\begin{array}{l}\text { Qualitative } \\
\text { description }\end{array}$ & $\begin{array}{c}\text { Comparative } \\
\text { analysis }\end{array}$ & $\begin{array}{l}\text { Empirical } \\
\text { analysis }\end{array}$ & $\begin{array}{c}\text { Theoretical review } \\
\text { and discussion }\end{array}$ & $\begin{array}{l}\text { Quantitative } \\
\text { description }\end{array}$ & $\begin{array}{l}\text { Diachronic } \\
\text { analysis }\end{array}$ & Total \\
\hline Chinese construction research & 409 & 3 & 14 & 121 & 14 & 6 & 567 \\
\hline $\begin{array}{l}\text { Foreign language construction } \\
\text { research }\end{array}$ & 49 & 2 & 10.5 & 13.5 & 8 & 1 & 84 \\
\hline $\begin{array}{l}\text { Comparative study of Chinese } \\
\text { and other language constructions }\end{array}$ & 5.5 & 24 & 1.5 & 4.5 & 2.5 & 0 & 38 \\
\hline Total & 463.5 & 29 & 26 & 139 & 24.5 & 7 & 689 \\
\hline
\end{tabular}

As shown in Figure 5, in the recent decade of Chinese CxG studies, there were increasing fluctuations in the number of qualitative descriptions, reaching a peak value of 53.5 and 56 in 2015 and 2019, respectively. Theoretical review and discussion had an initial rise in its trend, which then fluctuated and fell in numbers. The other four methods fluctuated gently under 10 per year.

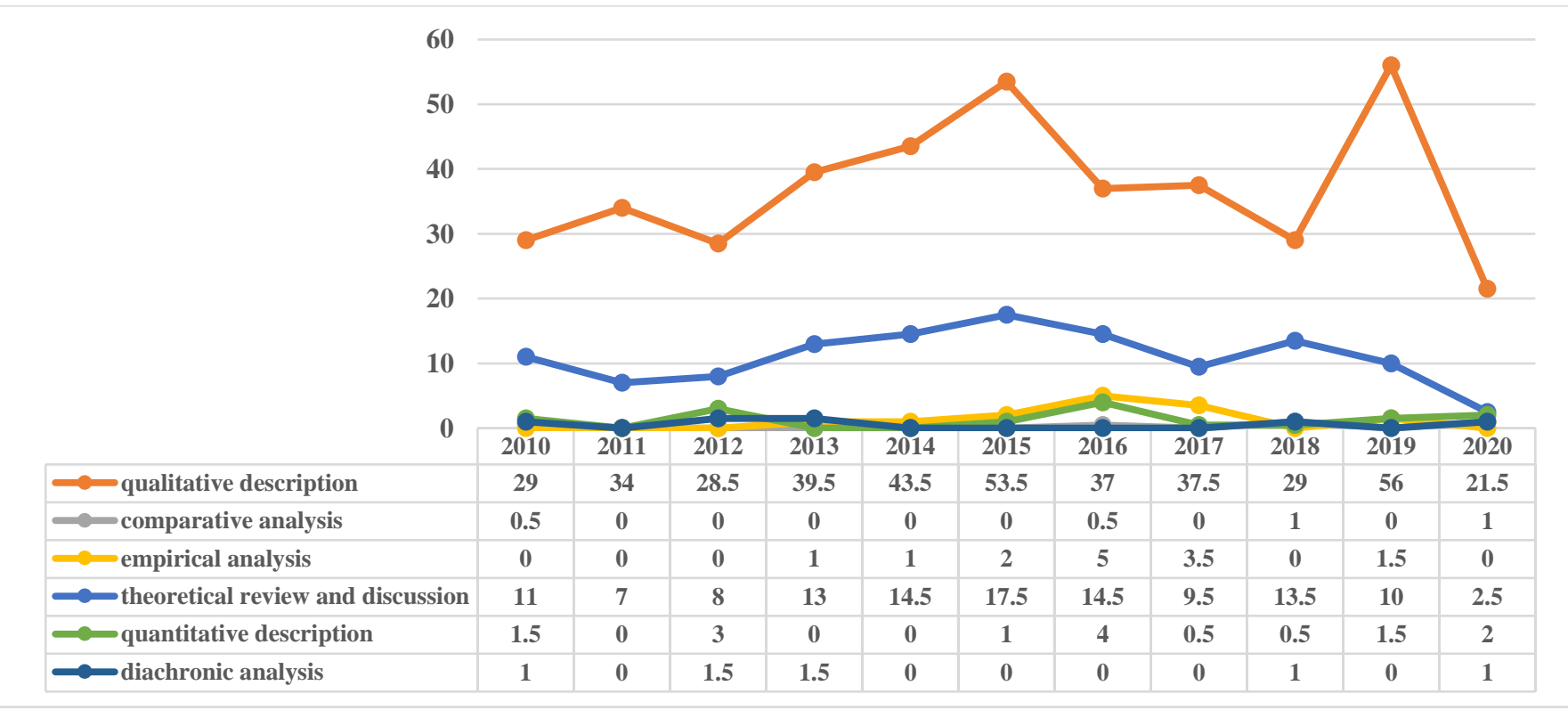

Figure 5. Research methods in Chinese construction grammar research

From Figure 6, it can be seen that in foreign language $\mathrm{CxG}$ research, qualitative description had always fluctuated at a high level. The quantity of theoretical review and discussion showed an upward trend, while empirical analysis and quantitative description showed a stable overall trend. There were only a few articles that adopted diachronic analysis. 


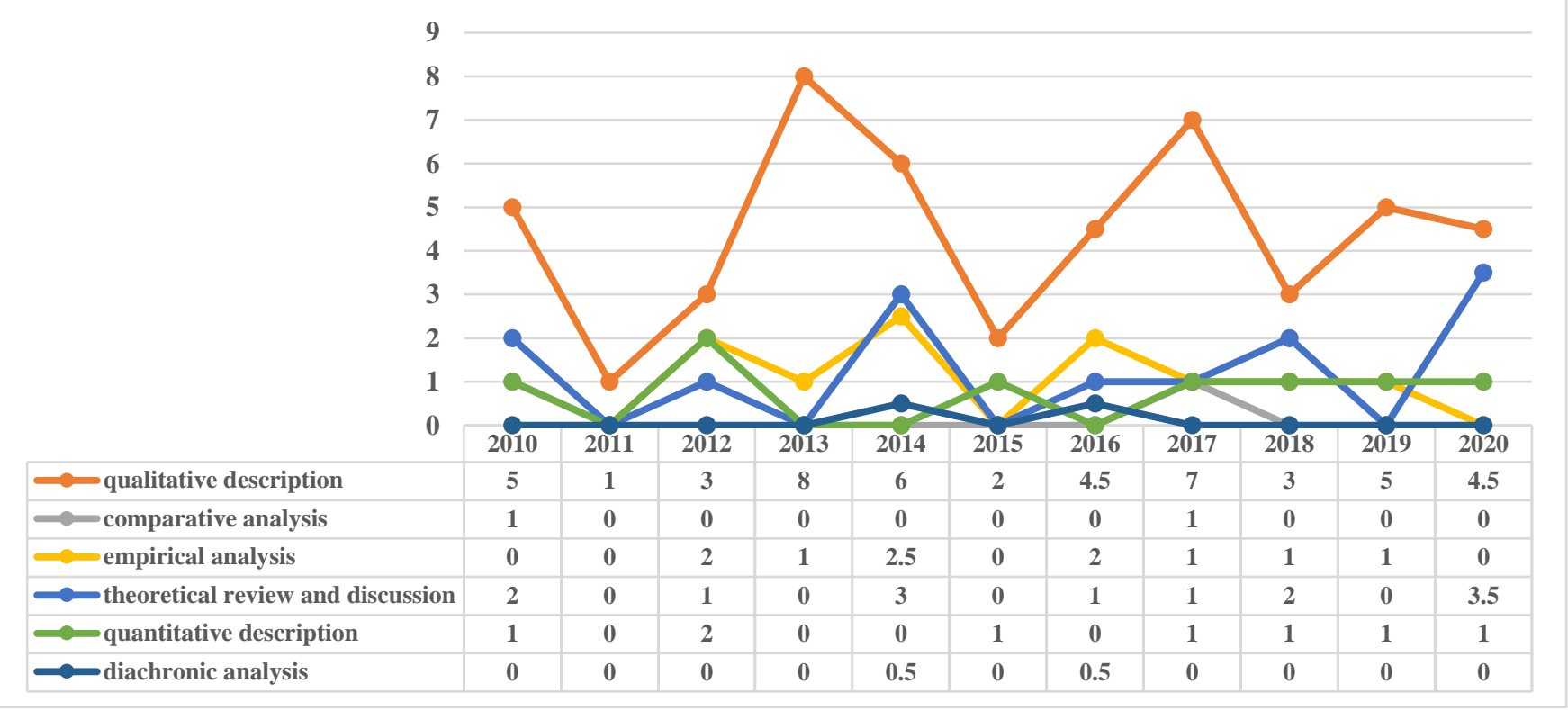

Figure 6. Research methods in foreign language construction research

In comparative studies, the tendency of comparative analysis showed substantial fluctuations before 2015. The number dropped to its lowest value in 2013, which was even lower than that of qualitative description. After 2016, its changes were relatively flat. There were quite a number of papers that used theoretical review and discussion before 2016, but almost none after that. It is worth noting that 2020 was the year with the most types of research methods. Except for diachronic analysis, the other four research methods appeared as shown in Figure 7.

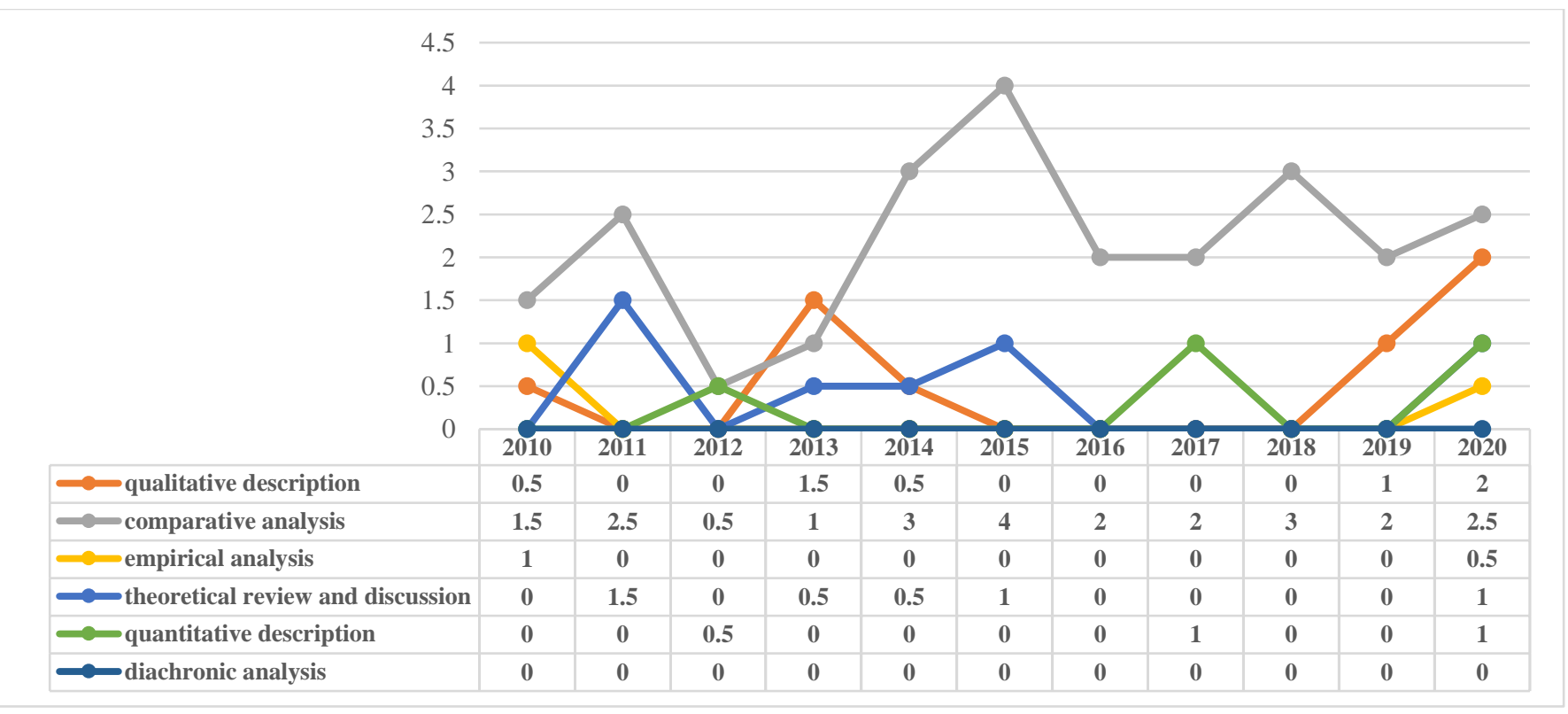

Figure 7. Research methods in comparative studies of Chinese and other language constructions

\section{Conclusion}

This paper presents a trend analysis of the research on construction grammar published in CSSCI journals from 2010 to 2020. The research topics mainly include Chinese construction research, foreign language construction research, as well as Chinese and other language construction research. In terms of quantity, 
there are relatively many studies on Chinese constructions. In contrast, comparative studies on Chinese constructions with other languages and on foreign constructions still require improvement.

In terms of publication years, 2015 and 2020 were the years with the highest and lowest number of publications, respectively. The number of papers on Chinese CxG reached its peak in 2015 and 2019 but dropped to its lowest point in 2020. Studies on foreign language $\mathrm{CxG}$ and comparative studies were most fruitful in 2014 and 2020, respectively. The number of studies was on the rise in the past three years, indicating that the academic community is paying more attention in this field. In regard to the research direction, ontology research was the main focus; acquisition research and teaching research are worthy for further exploration. Compare with Chinese $\mathrm{CxG}$ research and comparative studies, foreign language $\mathrm{CxG}$ research focuses more on teaching, which may provide research reference for the former two. In regard to the research content, case studies and theoretical studies were the most concerned, but studies on acquisition, pedagogy, and corpus were feeble, thus becoming the main direction of future $\mathrm{CxG}$ research. In terms of research methods, qualitative description as well as theoretical review and discussion were the most popular, while empirical, quantitative, and diachronic analyses were less frequently used. This phenomenon is related to the research direction and content. It has been predicted that the research on construction grammar would continue to heat up in the future, and there would be more research directions and contents along with diversified research methods.

\section{Disclosure statement}

The author declares that there is no conflict of interest.

\section{References}

[1] Wen X, Si W, 2021, 20 Years of Constructional Grammar Research in China: Retrospect and Prospect. Journal of PLA Foreign Languages Institute, (05): 43-51, 160-161.

[2] Shi C, 2021, Three Views of Construction: The Basic Ideas of Construction Grammar. Journal of Northeast Normal University (Philosophy and Social Sciences), (04): 1-15.

[3] Jin S, Lin Z, 2017, Atlas Analysis of International Metonymy Research Trends (2007-2016). Foreign Language Study, (03): 18-23.

[4] Fan Z, Guo Y, 2018, Development Trend and Frontier Dynamics of Foreign Constructional Grammar research - Analysis of Scientific knowledge Map Based on Visualization Technology. Journal of University of Science and Technology Beijing (Social Science Edition), (06): 56-63.

[5] Wu X, 2019, Visual Analysis of Domestic Construction Grammar Research Based on CiteSpace 5.0. Journal of Dongguan Institute of Technology, (6): 91-97.

[6] Zhu J, Cui X, 2012, A Review of the Theory and Application of Constructive Grammar. Modern Languages (Language Studies Edition), (10): 7-12.

[7] Zhang J, 2012, The Domestic Structure Theory Research Review of Grammar. Journal of Suzhou Institute of Education, (06): 53-57. 